\title{
Management of Axillary Web Syndrome after Breast Cancer: Evidence-Based Practice
}

\section{Tratamento da síndrome de rede axilar pós-câncer de mama: prática baseada em evidências}

\author{
Clarissa Medeiros da Luz ${ }^{1}$ Julia Deitos ${ }^{1}$ Thais Cristina Siqueira ${ }^{1}$ Marina Palú ${ }^{1}$ \\ Ailime Perito Feiber Heck ${ }^{1}$ \\ ${ }^{1}$ Physiotherapy Postgraduate Program, Center of Health and Sport \\ Sciences, Universidade do Estado de Santa Catarina (Udesc), \\ Florianópolis, SC, Brazil

\begin{abstract}
Address for correspondence Clarissa Medeiros da Luz, PhD, Programa de Pós-Graduação em Fisioterapia, Universidade do Estado de Santa Catarina (Udesc), Rua Pascoal Simone, 358-Coqueiros, 88080-350 Florianópolis-SC, Brazil (e-mail: clarissa.medeiros@udesc.br).
\end{abstract}

Rev Bras Ginecol Obstet 2017;39:632-639.

\begin{abstract}
Keywords

- physiotherapy

- axillary web syndrome

- conservative treatment

- rehabilitation

- cording

- lymphadenectomy

\section{Resumo}

Axillary web syndrome is characterized as a physical-functional complication that impacts the quality of life of women who have undergone treatment for breast cancer. The present study aims to verify the physiotherapy treatment available for axillary web syndrome after surgery for breast cancer in the context of evidence-based practice. The selection criteria included papers discussing treatment protocols used for axillary web syndrome after treatment for breast cancer. The search was performed in the MEDLINE, Scopus, PEDro and LILACS databases using the terms axillary web syndrome, lymphadenectomy and breast cancer, focusing on women with a previous diagnosis of breast cancer who underwent surgery with lymphadenectomy as part of their treatment. From the 262 studies found, 4 articles that used physiotherapy treatment were selected. The physiotherapy treatment was based on lymphatic drainage, tissue mobilization, stretching and strengthening. The four selected articles had the same outcome: improvement in arm pain and shoulder function and/or dissipation of the axillary cord. Although axillary web syndrome seems to be as frequent and detrimental as other morbidities after cancer treatment, there are few studies on this subject. The publications are even scarcer when considering studies with an interventional approach. Randomized controlled trials are necessary to support the rehabilitation resources for axillary web syndrome.

A síndrome da rede axilar (ou cordão axilar) é uma complicação físico-funcional que interfere na qualidade de vida de mulheres que foram submetidas a tratamento para o câncer de mama. O objetivo do presente estudo foi verificar os tratamentos fisioterapêuticos disponíveis para a síndrome da rede axilar após o tratamento cirúrgico do câncer de mama no contexto da prática clínica baseada em evidências. Utilizou-se como critério de inclusão artigos que discutissem protocolos de tratamento para a síndrome da rede axilar após o tratamento para o câncer de mama. A pesquisa foi
\end{abstract}

received

January 25, 2017

accepted

May 5, 2017

published online

July 12,2017
DOI https://doi.org/

$10.1055 / \mathrm{s}-0037-1604181$. ISSN $0100-7203$.
Copyright @ 2017 by Thieme Revinter

Publicações Ltda, Rio de Janeiro, Brazil

License terms

c) $(\oplus) \$$ 
Palavras-chave

- fisioterapia

- síndrome da rede axilar

- tratamento conservador

- reabilitação

- cordão axilar

- linfadenectomia realizada nas bases de dados MEDLINE, Scopus, PEDro e LILACS, utilizando como palavras-chave síndrome da rede axilar linfadenectomia e câncer de mama, com foco em mulheres com diagnóstico de câncer de mama que realizaram cirurgia com linfadenectomia como parte do tratamento. Dos 262 estudos encontrados, foram selecionados 4 artigos que utilizaram fisioterapia, os quais incluíram drenagem linfática, mobilização tecidual, alongamento e fortalecimento. Os quatro artigos selecionados tiveram desfechos similares: melhora da dor no membro superior e na função do ombro e/ou desaparecimento do cordão axilar. Embora a síndrome da rede axilar seja tão frequente e prejudicial quanto as outras morbidades após tratamento para o câncer, existem poucos estudos sobre esse tema. As publicações são ainda mais escassas quando se considera uma abordagem intervencionista. Estudos randomizados controlados são necessários para embasar as técnicas de reabilitação na síndrome da rede axilar após tratamento para o câncer de mama.

\section{Introduction}

Breast cancer is the most common cancer that affects women, with $\sim 1.050 .000$ new diagnoses per year worldwide. It represents the leading cause of death by cancer among women ${ }^{1}$ in developing countries. ${ }^{2}$ Surgery is the treatment of choice for this disease, and many times it includes sentinel lymph node biopsy (SLNB) or axillary lymph node dissection (ALND). These procedures are important to predict prognosis, reduce recurrence, and to plan an adequate treatment program. ${ }^{3}$ However, the axillary surgical approach leads to significant short or long-term complications, ${ }^{4}$ such as pain, paresthesia, lymphedema and decreased range of motion (ROM). ${ }^{5,6}$

Recently, the literature has pointed out a condition whose occurrence had been previously neglected. This condition is responsible for significant morbidity in the postoperative stage. ${ }^{4,6-8}$ Axillary web syndrome (AWS), or cording, is a dysfunction that usually occurs between the first and fifth weeks following breast cancer surgery. It is characterized by the presence of a visible and palpable stretched band under the skin, which is taut and painful during shoulder flexion or abduction. ${ }^{4,5,8-13}$ The cords are always present in the axilla, and may extend down into the medial ipsilateral arm. These cords frequently extend across the antecubital fossa and into the forearm, and occasionally to the radial aspect of the wrist and into the base of the thumb. ${ }^{5}$

In general, AWS is observed with the occurrence of two or three palpable cords under the skin, with no hyperemia, increased local temperature, or systemic symptoms. However, the patients may present significant loss in ROM, numbness, pain and tightness on the surgical ipsilateral upper limb, mainly when performing the shoulder abduction movement. $5,6,12,14,15$

Ferrandez and Serin ${ }^{16}$ initially described the presence of cords in 1996 as lymphatic thrombosis. Later, the term axillary web syndrome was chosen to describe this phenomenon. ${ }^{5,17,18}$ The etiology of AWS is unknown; however, Moskovitz et $\mathrm{al}^{5}$ and Ferrandez and Serin ${ }^{16}$ proposed that the pathogenesis would be related to the damage in the venous/lymphatic system, to the superficial venous/lymphatic hypercoagulability, as well as to the stasis and tissue damage caused by the axillary surgery. According to recent publications, all of these factors could result in thrombosis of the axillary vessels, the large superficial vessels, or the upper limb lymphatic vessels, originating palpable cords. ${ }^{4,10,18}$

The studies by Moskovitz et $\mathrm{al}^{5}$ and Leidenius et a $1^{10}$ showed that AWS has spontaneous resolution in a period of three to six months. However, it is known that during this phase the patients experience significant pain and reduced ROM in the compromised extremity, with a negative impact on or even preventing the use of radiation as an adjuvant therapy in the cases it would be indicated. ${ }^{6}$

Previous studies suggested that physiotherapy could alter the natural course of AWS, with full remission in a period of six to eight weeks. ${ }^{14,18}$ Therefore, physiotherapy has an important role in reducing the patients' exposure to complications caused by cording, improving their quality of life. Nevertheless, the treatment management and protocols are not yet precise in these cases.

Thereby, the search for data about evidence-based practices on the treatment of AWS after breast cancer surgery seems timely. Thus, the objective of this review was to determine the current evidence of available physiotherapy treatments for axillary web syndrome after breast cancer surgery.

\section{Methods}

The planning for the present review was based on the Cochrane Handbook for Systematic Reviews of Interventions, ${ }^{19}$ and adapted according to the recommendations of the Preferred Reporting Items for Systematic Reviews and Meta-Analysis (PRISMA) statement. ${ }^{20}$

\section{Eligibility Criteria}

Studies published on the MEDLINE, LILACS, PEDro or Scopus databases that explored AWS or its treatments were selected for this review, with no date restrictions.

All studies that explored physiotherapy treatment for AWS as a single therapy associated with other techniques 
or compared with other interventions or to placebo were included. Studies with no clear description of the interventions or techniques were excluded.

\section{Search Strategy}

The electronic search was performed on the Medline, Scopus, LILACS, and PEDro databases using Medical Subject Headings (MeSH) terms, with most common descriptors and expressions found in the literature. Scottish Intercollegiate Guidelines Network ${ }^{21}$ search filters were combined with an strategy developed by the authors to enable the search of clinical trials that included AWS treatment. This strategy was used for all databases, and adapted according to their specificities. The search was performed until September 14th, 2016. - Table 1 describes the specific search strategies on the selected databases.

\section{Study Selection}

All titles and summaries retrieved from each database were imported to a free bibliographical package (Mendeley Reference Manager, Elsevier, Amsterdam, Netherlands) and compiled in a central database in which four reviewers independently analyzed all the titles, keywords and summaries for relevance. When an agreement was not reached, a fifth reviewer was consulted to decide on the eligibility of the study. Studies that did not meet the inclusion criteria were not selected, and only those meeting the selection criteria were fully analyzed.

\section{Evaluation of the Methodological Quality of the Selected Studies}

The Strengthening the Reporting of Observational Studies in Epidemiology (STROBE) ${ }^{22,23}$ statement was used to verify the methodological quality of the selected studies. It has a scale that consists of 22 items, which were independently verified by 4 reviewers. Each study was classified as follows: A (studies that met $80 \%$ of the criteria), B (studies that met 50 to $80 \%$ of the criteria), and C (studies that met less than $50 \%$ of the criteria). ${ }^{23}$

\section{Results}

Upon completion of the search with the applicable database filters, 262 titles were identified, 45 on PEDro, 142 on MEDLINE,

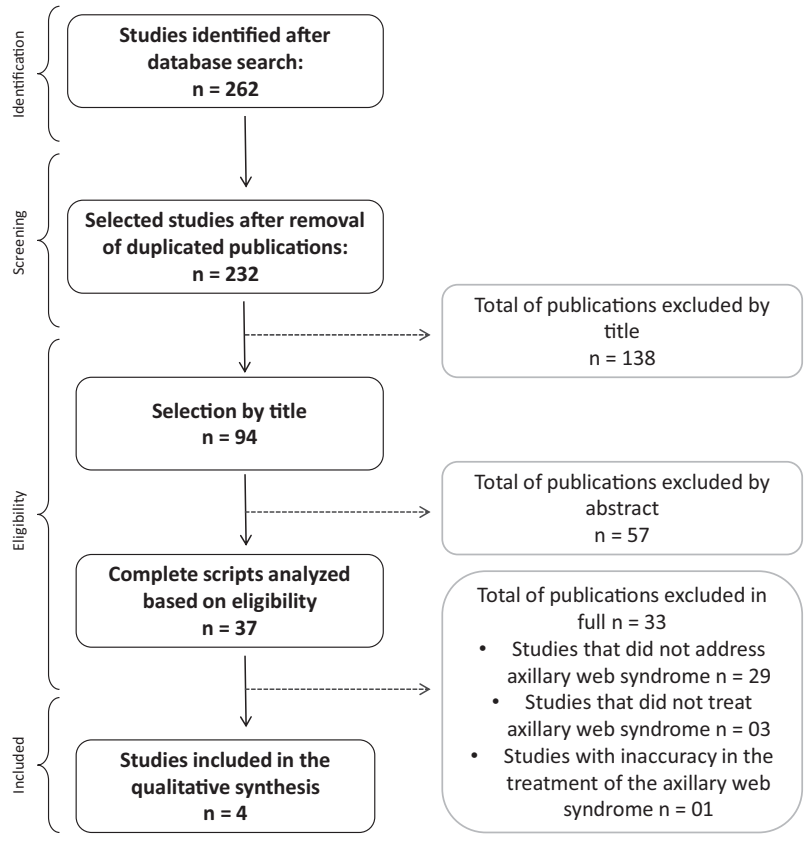

Fig. 1 Flowchart of the studies included after the selection process.

11 on LILACS, and 64 on Scopus. A total of 30 titles were found in more than one database and excluded, and 232 tittles were left for analysis. Subsequently, 94 and 37 manuscripts were considered potentially relevant for summary review and full manuscript review respectively. The studies had been published in English, Portuguese, Spanish, French, German, Dutch and Chinese. Finally, four studies published in English were selected. - Fig. 1 shows the detailed selection process.

Among the excluded studies, the majority did not mention the axillary cord as one of the post-breast cancer surgery morbidities, and some were limited to the identification of the axillary cord, with no therapeutic approach. The four selected studies had their main focus on physiotherapy treatment for axillary cord after breast cancer surgery.

Two case reports conducted in England and China, and two randomized controlled clinical trials (RCCTs) from Denmark and South Korea were included. The mean age observed in all studies varied from 39 to 60 years. On the case

Table 1 Search strategies for the selected databases: MEDLINE, Scopus and PEDro

\begin{tabular}{|l|}
\hline Search strategies \\
\hline MEDLINE \\
((Axillary dissection OR axillary lymph node dissection OR axillary surgery OR axillary web syndrome OR axillary clearance \\
OR axillary cording OR cording OR lymphatic cording) AND (breast cancer OR breast neoplasm) AND (physical therapy \\
modalities)) \\
\hline SCOPUS \\
Breast neoplasm AND axillary web syndrome OR cording AND physical therapy OR physiotherapy \\
\hline LILACS \\
(tw:((mh:(“breast cancer")) AND (mh:(“physiotherapy (techniques)")) AND (mh:(“axilla/surgery”)) AND (tw:(axillary web \\
syndrome)) OR (tw:(axillary cording)) OR (tw:(cording)) OR (tw:(lymphatic cording)))) \\
\hline PEDro \\
In the Problem field: muscle shortening, reduced joint compliance; in the Body Part field: upper arm, shoulder or shoulder \\
girdle; in the Subdiscipline field: oncology; in the Method field: clinical trial; when searching: match all search terms AND. \\
\hline
\end{tabular}


reports, the duration of the treatment varied between two and four weeks. In one RCCT, the subjects underwent 12 sessions with a frequency of 2 sessions per week and followups at 7, 13, 26 and 56 postoperative weeks. In the other one, there were three weekly sessions for four weeks. All selected studies showed the same outcome: axillary cords resolved after treatment/follow-up, or improvement in pain and shoulder function. Only the two RCCTs were categorized as A studies based on the evidence hierarchy by the STROBE classification $^{22,23}$ (- Table 2).

On the RCCT by Lauridsen et al, ${ }^{24} 139$ patients who underwent levels I and II lymph node dissections followed by radiation (45\%) and/or modified radical mastectomy with or without levels I and II axillary dissections (55\%) were enrolled to evaluate the effects of physiotherapy on shoulder function. For such, 12 physiotherapy sessions of 60 minutes each were performed, including mobilization, relaxation and strength training of the shoulder, vein pump therapy, as well as scar tissue mobilization and patient encouragement to perform the exercises at home. The difference between the groups was related to the onset of the treatment: group A started the treatment between the 6 th and 8 th postoperative weeks, and group B, after the 26 th postoperative week. There was a significant improvement in shoulder function in group A compared with group B starting at the seventh postoperative week. Besides, the development of AWS was similar in both groups, with no changes based on the type of surgery or radiation therapy. The number of cording cases decreased throughout the follow-up period, affecting $57 \%$ of the participants on the 7 th week, $31 \%$ on 13 th week, $15 \%$ on 26 th week, and none after the 56th postoperative week.

The aim of the study by Fourie and Robb ${ }^{14}$ was to report the treatment of a 47-year-old patient who developed AWS on the 22nd day after modified radical mastectomy with unilateral axillary dissection. Due to progressive loss of shoulder movements upon the onset of AWS, which was visible from the axilla to the wrist, the patient started axillary cord stretching in abduction, self-mobilization, as well as slight circular mobilization and soft tissue mobilization of the chest wall. The treatment was performed over 10 sessions of 30 to 45 minutes each. After 26 days of treatment, the patient returned to work and had complete resolution of the syndrome, including an improvement in the pain and shoulder mobility 16 weeks postoperatively. Thus, the

Table 2 Criteria for the evaluation of the methodological quality of the selected studies according to the Strengthening the Reporting of Observational Studies in Epidemiology (STROBE) statement ${ }^{22}$

\begin{tabular}{|c|c|c|c|c|c|}
\hline \multicolumn{2}{|l|}{ Section/topic } & \multirow{2}{*}{$\begin{array}{l}\text { Lauridsen et } \mathrm{al}^{24} \\
(2005) \\
\mathrm{Y}\end{array}$} & \multirow{2}{*}{$\begin{array}{l}\begin{array}{l}\text { Fourie and Robb } \\
\text { (2009) }\end{array} \\
Y \\
\end{array}$} & \multirow{2}{*}{$\begin{array}{l}\text { Wei et al }{ }^{15} \\
(2013) \\
Y\end{array}$} & \multirow{2}{*}{$\begin{array}{l}\text { Cho et } \text { al }^{25} \\
(2016) \\
Y\end{array}$} \\
\hline & 1 Title and abstract & & & & \\
\hline \multirow[t]{2}{*}{ Introduction } & 3 Background/rationale & $\mathrm{Y}$ & $Y$ & $\mathrm{Y}$ & $Y$ \\
\hline & 4 Objectives & $\mathrm{Y}$ & $\mathrm{N}$ & $\mathrm{N}$ & $Y$ \\
\hline \multirow[t]{8}{*}{ Methods } & 5 Study design & $\mathrm{Y}$ & $\mathrm{N}$ & $\mathrm{N}$ & $\mathrm{Y}$ \\
\hline & 6 Participants & $\mathrm{Y}$ & $\mathrm{Y}$ & $\mathrm{N}$ & $\mathrm{Y}$ \\
\hline & 7 Variables & $\mathrm{Y}$ & $Y$ & $Y$ & $Y$ \\
\hline & 8 Data sources/measurement & $\mathrm{Y}$ & $\mathrm{Y}$ & $\mathrm{Y}$ & $\mathrm{Y}$ \\
\hline & 9 Bias & $\mathrm{N}$ & $\mathrm{N}$ & $\mathrm{Y}$ & $\bar{Y}$ \\
\hline & 10 Study size & $\mathrm{Y}$ & $\mathrm{N}$ & $\mathrm{N}$ & $\mathrm{Y}$ \\
\hline & 11 Quantitative variables & $\mathrm{Y}$ & $\mathrm{N}$ & $\mathrm{N}$ & $\mathrm{Y}$ \\
\hline & 12 Statistical methods & $\bar{Y}$ & $\mathrm{~N}$ & $\mathrm{~N}$ & $\bar{Y}$ \\
\hline \multirow[t]{5}{*}{ Results } & 13 Participants & $\mathrm{Y}$ & $\mathrm{N}$ & $\mathrm{N}$ & $\mathrm{Y}$ \\
\hline & 14 Descriptive data & $\mathrm{Y}$ & $\mathrm{N}$ & $\mathrm{Y}$ & $\mathrm{Y}$ \\
\hline & 15 Outcome data & $\mathrm{Y}$ & $\mathrm{Y}$ & $\mathrm{Y}$ & $Y$ \\
\hline & 16 Main results & $\mathrm{Y}$ & $\mathrm{Y}$ & $\mathrm{Y}$ & $\mathrm{Y}$ \\
\hline & 17 Other analysis & $Y$ & $\mathrm{~N}$ & $\mathrm{~N}$ & $\mathrm{~N}$ \\
\hline \multirow[t]{4}{*}{ Discussion } & 18 Key results & $\mathrm{Y}$ & $\mathrm{Y}$ & $\mathrm{Y}$ & $\mathrm{Y}$ \\
\hline & 19 Limitations & $\mathrm{N}$ & $\mathrm{N}$ & $\mathrm{N}$ & $\mathrm{Y}$ \\
\hline & 20 Interpretation & $Y$ & $Y$ & $\mathrm{~N}$ & $\mathrm{Y}$ \\
\hline & 21 Generalizability & $\mathrm{N}$ & $\mathrm{N}$ & $\mathrm{N}$ & $\mathrm{Y}$ \\
\hline Other information & 22 Funding & $\mathrm{N}$ & $\mathrm{N}$ & $\mathrm{N}$ & $\mathrm{N}$ \\
\hline \multicolumn{2}{|l|}{ Total } & $18 / 22-81 \%$ & $10 / 22-45 \%$ & $9 / 22-40 \%$ & $20 / 22-90 \%$ \\
\hline \multicolumn{2}{|l|}{ Final classification } & A & $\mathrm{C}$ & C & A \\
\hline
\end{tabular}

Abbrreviations: Y, yes; N, no. 
physiotherapy intervention was considered efficient. However, the authors acknowledge the need for further investigations to develop a standard physiotherapy treatment for this syndrome.

The study by Wei et $\mathrm{al}^{15}$ described the treatment of a case of AWS secondary to breast-conserving surgery and negative SLNB. On the third day after her second procedure for margin excision, with no axillary dissection, the patient developed axillary cords. During her follow-up, the cords extended to her elbow and the superior external quadrant of the ipsilateral breast. The authors report that besides the pharmacological treatment, she underwent massage sessions on the cord area, and performed shoulder abduction exercises. However, there are no details about the recommended exercises. After two weeks of treatment, she presented decreased pain and increased ROM on shoulder abduction, as well as an improvement in the axillary cording. On the third week follow-up, a physical exam showed full recovery of ROM and absence of pain. Moreover, the axillary cords were visible but no longer palpable, even though the patient still reported numbness and tightness.

Recently, Cho et $\mathrm{al}^{25}$ designed a randomized clinical trial to evaluate the effects of physiotherapy combined with manual lymphatic drainage on shoulder function, pain and lymphedema compared with isolated physical therapy in breast cancer patients with AWS. The 48 participants recruited for the study had pain in the arm area and presented palpable or visible cords on the arm for at least four weeks after surgery. They were submitted to three weekly sessions of a physiotherapy program for four weeks, which consisted of stretching and strengthening exercises for upper limb tissue mobilization, scapular mobilization and shoulder ROM exercises, and a specific program for AWS. The participants were divided into two groups: the first group only performed the exercise program, and the second underwent the exercise program and 30 minutes of manual lymphatic drainage daily 5 times for 1 week, with instructions to perform it at home themselves for the other two to four weeks of the program. There was a significant improvement in pain and arm volume in the group that performed manual lymphatic drainage. In addition, both groups showed improvements in quality of life, strength and shoulder function after the interventions. There was no significant difference related to visible cording between the groups, and it was present in $28.5 \%$ of the patients who underwent exercises combined with manual lymphatic drainage, and in $35 \%$ of the patients who only performed exercises.

- Table 3 details the main methodological aspects and the results of the studies selected for the present systematic review.

\section{Discussion}

According to the results of the present systematic review, all four studies showed that AWS developed between one and six months postoperatively. Exercises for shoulder ROM and for strengthening and relaxation, instruction for lymphatic drainage and mobilization of scar tissue, as well as stretching and manual therapy with massages and tissue mobilization composed the treatment for AWS. The physiotherapy interventions in these studies varied from 10 to 12 sessions. The results show evidence of improvements in the ROM of the shoulder and patient well-being, and the resolution of pain and reduction of cords during the physical examination, with the exception of the study by Cho et $\mathrm{al}^{25}$ an RCCT in which the authors did not observe differences between the groups for visible cords at the end of the treatment.

Although the study by Cho et $\mathrm{al}^{25}$ reports the incidence of visible cords in $28.5 \%$ of the patients who underwent exercises combined with manual lymphatic drainage, and in 35\% of the patients who only performed exercises, without making it clear if there were any differences in inspection and palpation of the cords compared to the initial parameters, the significant improvement in arm pain in the group that underwent manual lymphatic drainage, and the improvement in shoulder function after interventions observed in both groups indicate a possible improvement in AWS itself.

Therefore, the results of the four studies show the efficacy of physiotherapy as a conservative intervention for AWS after breast cancer treatment. However, these results should be carefully analyzed, as the scientific evidence level of two of the selected studies did not present appropriate methodological accuracy.

The axillary surgical approach has been important in the treatment of breast cancer. However, the dissection of lymph nodes may lead to comorbidities such as AWS. ${ }^{26}$ The incidence of AWS is different among women who underwent breast surgery and SLNB and those who underwent ALND; it varies from 11.7 to $20 \%$, and from 38 to $72 \%$ respectively. ${ }^{6,18,27,28}$ The development of cords occurs from two to six weeks after surgery and is, therefore, associated with the initial phases of postoperative wound healing. The literature suggests that adhesion formed around the lymphatic veins could be responsible for AWS and venous thrombosis. Yet, there is still little evidence to support this theory. ${ }^{14}$

Fourie and Robb ${ }^{14}$ mention studies that point AWS as a self-limiting comorbidity, with spontaneous resolution in about three months. ${ }^{10,14}$ However, the study by Torres Lacomba et $\mathrm{al}^{18}$ indicates that physiotherapy for AWS could shorten the natural course of the syndrome to six to eight weeks.

Several studies indicate the use of physiotherapy for the treatment of AWS in the form of active exercises, Kabat diagonals, pendulum exercises, stretching, myofascial techniques, manual therapy, cryotherapy, thermotherapy ${ }^{14,29,30}$ and active and passive exercises that should be implemented early. ${ }^{18}$ When the limitation is severe and the pain level is high, it is suggested that the treatment begin with mild gravity assisted exercises, such as Codman pendulum exercises. With the improvement in the limiting symptoms, active mobilization of the shoulder in flexion, abduction, and internal and external rotations should be implemented. ${ }^{29}$

The myofascial techniques and manual therapy are also used on lymphatic cords. The study conducted by Cheville and Tchou ${ }^{29}$ instructs therapists and patients to perform 


\begin{tabular}{|c|c|c|c|c|c|c|c|c|}
\hline 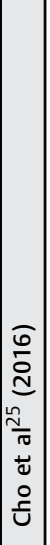 & 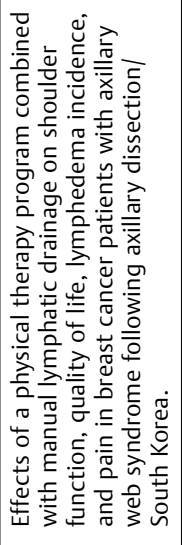 & 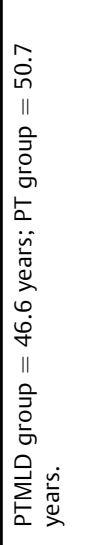 & $\stackrel{\infty}{\sim}$ & 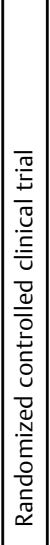 & 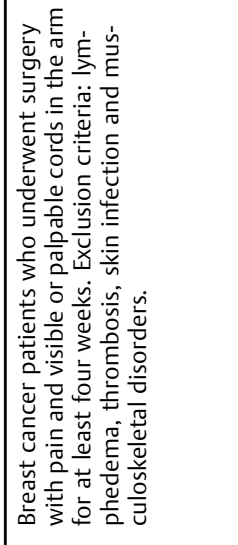 & 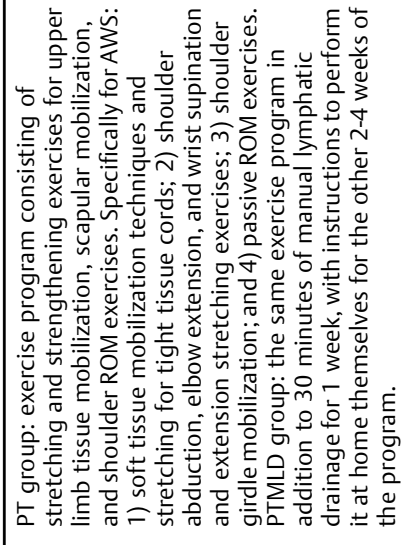 & 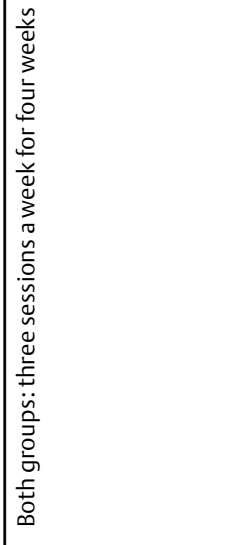 & 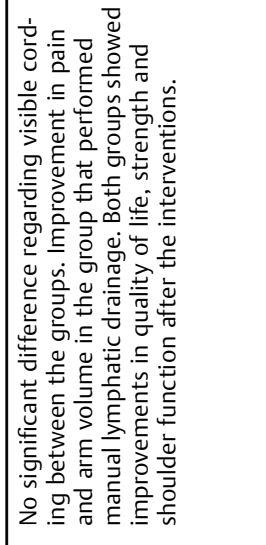 \\
\hline 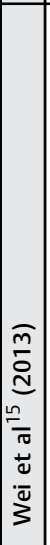 & 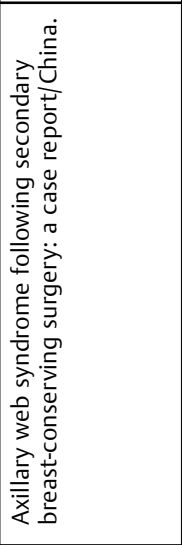 & 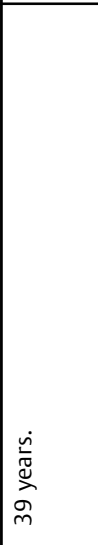 & - & 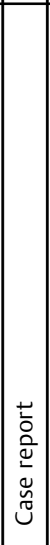 & 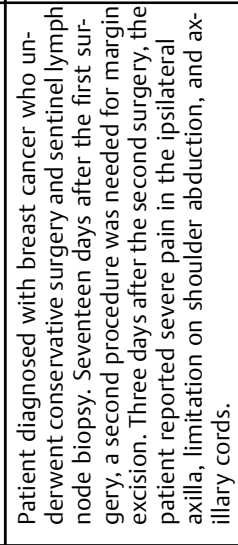 & 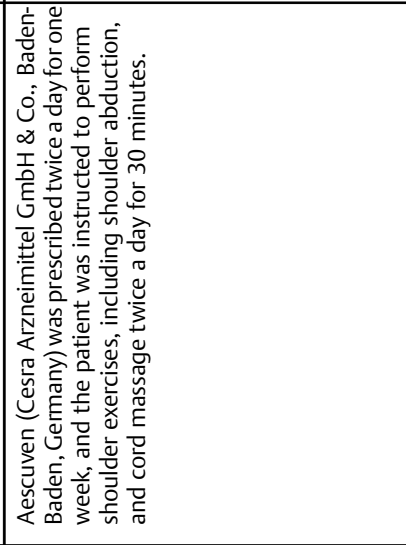 & 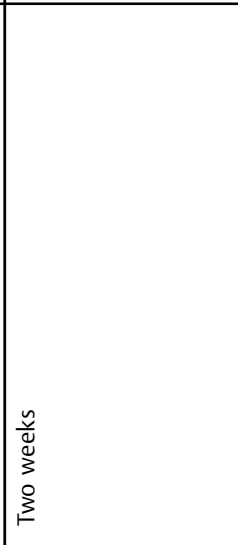 & 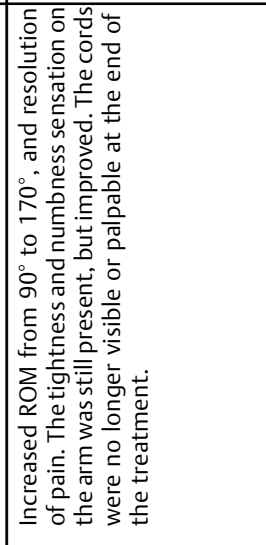 \\
\hline 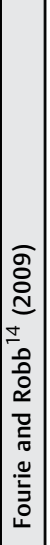 & 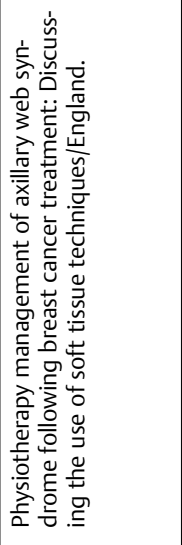 & 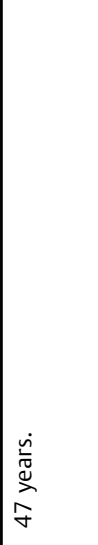 & - & 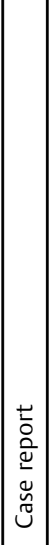 & 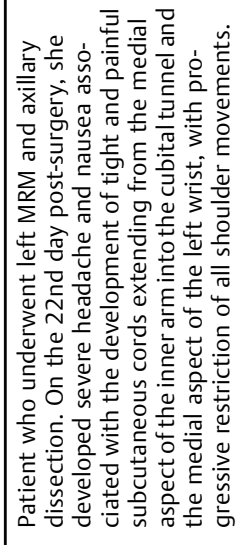 & 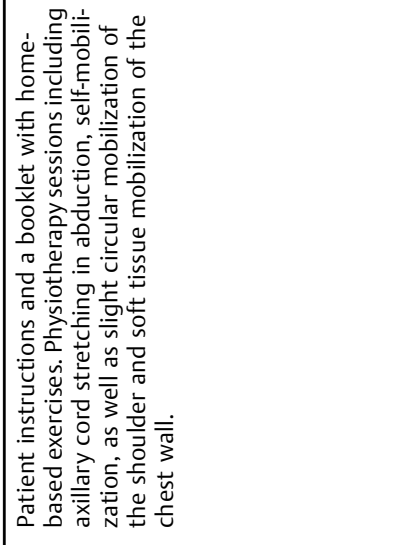 & 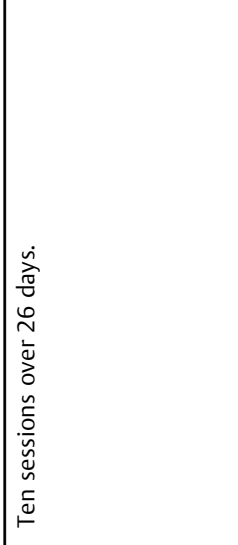 & 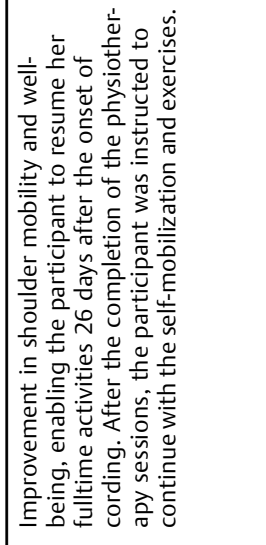 \\
\hline 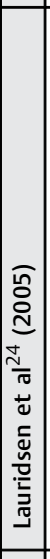 & 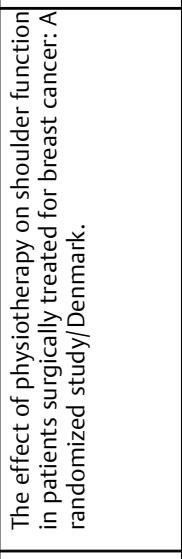 & 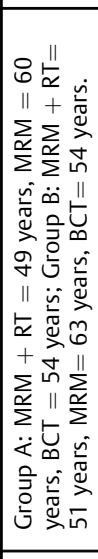 & 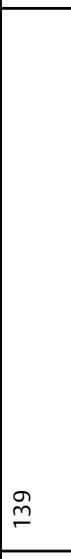 & 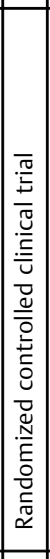 & 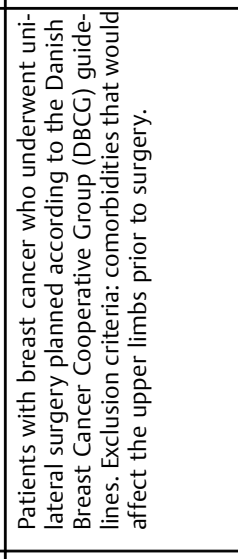 & 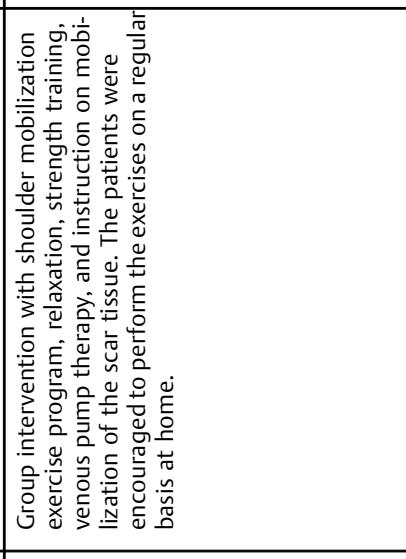 & 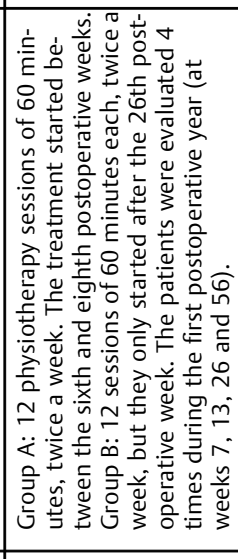 & 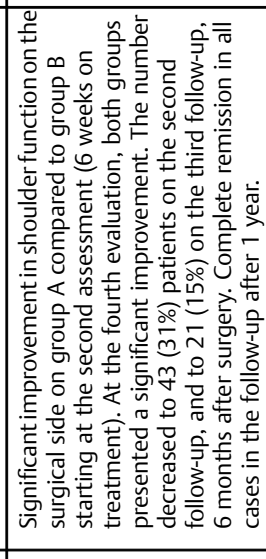 \\
\hline & 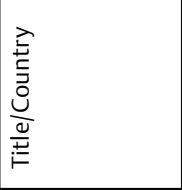 & 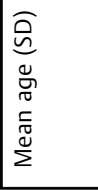 & 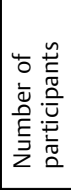 & 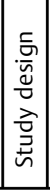 & 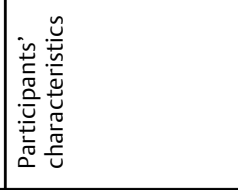 & 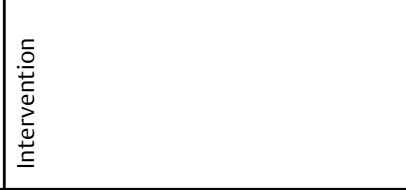 & 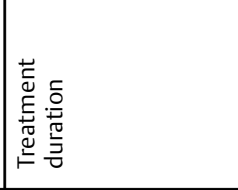 & $\begin{array}{l}\frac{\tilde{v}}{\vec{J}} \\
\stackrel{⿹}{\dddot{2}}\end{array}$ \\
\hline
\end{tabular}


manual techniques to release the cords. Torres Lacomba et $\mathrm{al}^{18}$ mention specific manual lymphatic drainage using the thumb to make the lymphatic cords more flexible. Still, there is no evidence that such techniques contribute to the improvement of AWS.

Although suggested by Cheville and Tchou, ${ }^{29}$ thermotherapy should be used with caution. Heat makes collagen more flexible, consequently improving shoulder ROM, but the extensive exposure to heat increases vasodilatation and, therefore, the risk of lymphedema. ${ }^{31}$ Besides, patients presenting intercostobrachial nerve lesion, another common morbidity related to breast cancer treatment, have increased risk of skin burning due to reduced sensitivity in the area. ${ }^{29}$

It is possible that the lack of studies on this subject could be explained by the relatively short period since this morbidity has been described in the literature. As Fukushima et $\mathrm{al}^{26}$ mentioned, AWS has not yet had a complete review of its complications and treatments and, until a few years ago, it had no proper definition. Despite the deficiency in studies describing the pathophysiology of AWS, there is a tendency of recent publications to describe its etiology and characteristics using complementary exams such as ultrasonography and magnetic resonance imaging. ${ }^{8,9}$ A recent study is proposing the use of a new self-assessment questionnaire to improve diagnosis and patient education to evaluate the presence of AWS. ${ }^{28}$

Previous studies suggesting the lack of efficacy of physiotherapy on the treatment of AWS have not specified the proposed exercise protocol. ${ }^{29,32}$ Furthermore, the remaining studies excluded from the present review had no description of the methods used, the AWS examination, or the selected type and frequency of the treatment. Other studies described the treatment but not the efficacy analysis on the results following intervention or patient education.

It is important to point out the quality of the selected studies, as the level of scientific evidence on the manuscripts was not quite accurate in terms of methodology. Only two studies were classified as STROBE category A, and the other two were classified as category $C$, as it applies to case reports. None of these two studies with lower levels of scientific evidence described the study design, the variables used, and/ or the research limitations. Nevertheless, these studies are still important to understand this morbidity, considering that the lack of publications on this subject contributes to the low evidence on this matter.

\section{Conclusion}

Surgeries are often the first treatment choice for breast cancer, and may result in several complications, including AWS, which causes pain and ROM limitation on the ipsilateral upper limb. The complete or partial mobility limitation of the arm may delay the beginning of the radiation therapy. Thus, it is extremely important to recognize all available resources to treat this complication, enabling the early initiation of adjuvant therapies.

Although AWS has spontaneous resolution within a few weeks, and besides the lack of methodological evidence on
AWS and its treatment, the studies selected in this review showed the efficacy of physiotherapy as a conservative technique for the treatment of AWS following breast cancer surgery. The studies included programs with exercises to increase shoulder ROM, relaxation, strengthening, and instructions for lymphatic drainage, stretching and manual therapy, such as massage and tissue mobilization. These interventions lead to improvements in ROM, resolution of pain, reduction of cords on inspection and, consequently, improvements in the well-being of women.

The lack of scientific interest on this subject suggests that this complication may be underestimated or neglected on the clinical practice. Therefore, new prospective controlled studies with high methodological accuracy would be valuable to support the evidence-based practice. This is particularly important, as AWS affects the functionality of women with progressive pain that evolves into partial or complete immobility of the affected extremity.

\section{References}

1 DeSantis C, Ma J, Bryan L, Jemal A. Breast cancer statistics, 2013. CA Cancer J Clin 2014;64(01):52-62

2 Torre LA, Bray F, Siegel RL, Ferlay J, Lortet-Tieulent J, Jemal A. Global cancer statistics, 2012. CA Cancer J Clin 2015;65(02):87-108

3 Nogueira PVG, Guirro ECO, Guirro RRJ, Palauro VA. [Effects of proprioceptive neuromuscular facilitation on functional performance of mastectomized women]. Fisioter Bras 2005;6(01): 28-35 Portuguese

4 Reedijk M, Boerner S, Ghazarian D, McCready D. A case of axillary web syndrome with subcutaneous nodules following axillary surgery. Breast 2006;15(03):411-413

5 Moskovitz AH, Anderson BO, Yeung RS, Byrd DR, Lawton TJ, Moe RE. Axillary web syndrome after axillary dissection. Am J Surg 2001;181(05):434-439

6 Koehler LA, Blaes AH, Haddad TC, Hunter DW, Hirsch AT, Ludewig PM. Movement, function, pain, and postoperative edema in axillary web syndrome. Phys Ther 2015;95(10):1345-1353

7 Bernas MJ. Axillary web syndrome, the lost cord, and lingering questions. Lymphology 2014;47(04):153-155

8 Leduc $\mathrm{O}$, Fumière $\mathrm{E}$, Banse $\mathrm{S}$, et al. Identification and description of the axillary web syndrome (AWS) by clinical signs, MRI and US imaging. Lymphology 2014;47(04):164-176

9 Koehler LA, Hunter DW, Haddad TC, Blaes AH, Hirsch AT, Ludewig PM. Characterizing axillary web syndrome: ultrasonographic efficacy. Lymphology 2014;47(04):156-163

10 Leidenius M, Leppänen E, Krogerus L, von Smitten K. Motion restriction and axillary web syndrome after sentinel node biopsy and axillary clearance in breast cancer. Am J Surg 2003;185(02):127-130

11 Torres Lacomba M, Yuste Sánchez MJ, Zapico Goñi A, et al. Effectiveness of early physiotherapy to prevent lymphoedema after surgery for breast cancer: randomised, single blinded, clinical trial. BMJ 2010;340:b5396

12 Leduc $\mathrm{O}$, Sichere M, Moreau A, et al. Axillary web syndrome: nature and localization. Lymphology 2009;42(04):176-181

13 Fukushima KF, Carmo LA, Borinelli AC, Ferreira CW. Frequency and associated factors of axillary web syndrome in women who had undergone breast cancer surgery: a transversal and retrospective study. Springerplus 2015;4:112

14 Fourie WJ, Robb KA. Physiotherapy management of axillary web syndrome following breast cancer treatment: discussing the use of soft tissue techniques. Physiotherapy 2009;95(04): 314-320 
15 Wei P, Zhu L, Chen K, Jia W, Hu Y, Su F. Axillary web syndrome following secondary breast-conserving surgery: a case report. World J Surg Oncol 2013;11:8

16 Ferrandez J, Serin D. Rééducation et cancer du sein. Paris: Masson; 1996.

17 Aydogan F, Belli AK, Baghaki S, Karabulut K, Tahan G, Uras C. Axillary web syndrome after sentinel node biopsy. Breast Care (Basel) 2008;3(04):277-278

18 Torres Lacomba M, Mayoral Del Moral O, Coperias Zazo JL, Yuste Sánchez MJ, Ferrandez JC, Zapico Goñi A. Axillary web syndrome after axillary dissection in breast cancer: a prospective study. Breast Cancer Res Treat 2009;117(03):625-630

19 Higgins J, Green S. Cochrane handbook for systematic reviews of interventions [Internet]. Chichester: Wiley; 2011 [cited $2012 \mathrm{Mar}$ 20]. Available from: https://dhosth.files.wordpress.com/2011/12/ cochrane-handbook-for-systematic-reviews-of-interventions.pdf

20 Liberati A, Altman DG, Tetzlaff J, et al. The PRISMA statement for reporting systematic reviews and meta-analyses of studies that evaluate healthcare interventions: explanation and elaboration. BMJ 2009;339:b2700

21 Scottish Intercollegiate Guidelines Network [Internet]. Search filters. 2014 [cited 2015 Feb 17]. Available from: http://www. sign.ac.uk/methodology/filters.html

22 Malta M, Cardoso LO, Bastos FI, Magnanini MM, Silva CM. STROBE initiative: guidelines on reporting observational studies. Rev Saude Publica 2010;44(03):559-565

23 von Elm E, Altman DG, Egger M, Pocock SJ, Gøtzsche PC, Vandenbroucke JP; STROBE Initiative. The Strengthening the Reporting of Observational Studies in Epidemiology (STROBE) statement: guidelines for reporting observational studies. Int J Surg 2014; 12(12):1495-1499
24 Lauridsen MC, Christiansen P, Hessov I. The effect of physiotherapy on shoulder function in patients surgically treated for breast cancer: a randomized study. Acta Oncol 2005;44(05):449-457

25 Cho Y, Do J, Jung S, Kwon O, Jeon JY. Effects of a physical therapy program combined with manual lymphatic drainage on shoulder function, quality of life, lymphedema incidence, and pain in breast cancer patients with axillary web syndrome following axillary dissection. Support Care Cancer 2016; 24(05):2047-2057

26 Fukushima KFP, Silva HJ, Ferreira CWS. Alterações vasculares resultantes da abordagem cirúrgica da axila: uma revisão da literatura. Rev Bras Mastologia. 2011;21(02):91-98

27 Bergmann A, Mendes VV, de Almeida Dias R, do Amaral E Silva B, da Costa Leite Ferreira MG, Fabro EA. Incidence and risk factors for axillary web syndrome after breast cancer surgery. Breast Cancer Res Treat 2012;131(03):987-992

28 Nevola Teixeira LF, Veronesi P, Lohsiriwat V, et al. Axillary web syndrome self-assessment questionnaire: Initial development and validation. Breast 2014;23(06):836-843

29 Cheville AL, Tchou J. Barriers to rehabilitation following surgery for primary breast cancer. J Surg Oncol 2007;95(05):409-418

30 Pou Chaubron M, Almendáriz Juárez A, Peñalva Padial G, Casermeiro Cortés J. El síndrome axillary-web, frecuente, pero infradiagnosticado. Rehabilitación. 2012;46(02):175-178

31 International Society of Lymphology. The diagnosis and treatment of peripheral lymphedema: 2013 Consensus Document of the International Society of Lymphology. Lymphology 2013; 46(01):1-11

32 Craythorne E, Benton E, Macfarlane S. Axillary web syndrome or cording, a variant of mondor disease, following axillary surgery. Arch Dermatol 2009;145(10):1199-1200 